\title{
Narrar el cotidiano de los portadores de la revolución social: proyecto político y artístico del movimiento vanguardista Rosa Náutica, Valparaíso, Chile (1922-1923).*
}

Narrating the daily life of the carriers of the social revolution: political and artistic project of Rosa Náutica avant-garde movement, Valparaíso, Chile (1922-1923).

\author{
Jorge Muñoz Sougarret**
}

\begin{abstract}
Resumen: El artículo se centra en el grupo artístico vanguardista de Valparaíso llamado Rosa Náutica, que entre 1922 y 1923 intentó retratar el cotidiano de la población de los cerros del puerto, igualmente este grupo se caracterizó por difundir manifiestos que apelaban a una revolución social guiada por los sectores desposeídos, y no por intelectuales. En gran medida aquella apelación nacía de la relación entablada con un exiliado húngaro del régimen socialista de Bela Kun. Las investigaciones previas a este grupo vanguardista no han destacado su mirada social, subsumiéndola a discusiones sobre el estilo de escritura más que a su fondo. Por tanto consideramos importante revalorar su mirada de los sectores desposeídos de Valparaíso, junto con el proyecto político que el grupo enarbolaba, en gran medida para construir una mirada más amplia sobre el desarrollo de la literatura social chilena de la década de 1920.
\end{abstract}

Palabras clave: Exilio político, Movimientos artísticos de vanguardia, Revolución social, Pobreza urbana

\begin{abstract}
The article focuses on the avant-garde artistic group of Valparaiso called Rosa Nautica, which between 1922 and 1923 tried to portray the daily life of the population of the hills of the port. Also, this group was characterized by spreading the manifestos that appealed to a social revolution led by the dispossessed sectors, not the intellectuals, whose appeal largely stemmed from the relationship established with one exiled Hungarian Socialist Bela Kun regime. Previous research about this avant-garde group has not highlighted his social gaze, subsuming discussions about the writing style more than his background. Therefore we consider it important to reevaluate his vision of the dispossessed sectors of Valparaiso, along with the political project that the group brandished, largely to build a broader view of the development of Chilean social literature of the 1920s.
\end{abstract}

Keywords: Political exile, Avant-Garde movements, Social Revolution, Urban poverty

\footnotetext{
* Resultado del Proyecto 72026 Fondo del Libro: Investigación, "El movimiento Rosa Náutica de Valparaíso y su irradiación a la vanguardia húngara de entreguerras". La investigación, discusión y ejecución de este proyecto se llevó a cabo junto al señor Cristián Olivos, artista visual de Valparaíso.

${ }^{* *}$ Chileno, Magíster en Ciencias Humanas c/m Historia por la Universidad de Los Lagos (2009), Doctorando en Historia por la Pontificia Universidad Católica, Académico de la Universidad de Los Lagos, sede Osorno: jorge.munoz@ulagos.cl
} 


\section{Introducción}

La utilización de personajes extracción popular en la literatura ha sido una práctica tradicional, que se popularizó durante el siglo XIX europeo donde tales personajes avanzaron desde puestos secundarios hasta roles protagónicos en novelas románticas y realistas. Su ingreso como personajes también posibilitó la expansión a nuevas temáticas, empero era evidente que en muchos de estos escritos subyacía un discurso moralizante hacia el mundo popular, que apuntaba a la construcción de antinomias, por un lado la pobreza digna (representada en sujetos populares con fuerte apego a las tradiciones religiosas y sociales, y plenamente comprometidos con las formas imperantes de relaciones laborales) y por otro la pobreza decadente (que hablaba de individuos carentes de disciplina laboral, volcados a la satisfacción personal de sus deseos y carentes de religión).

Ejemplos de este cuño podemos encontrar tanto en la literatura europea como americana, pero luego de iniciada la primera guerra mundial emergieron movimientos artísticos que propusieron una mirada distinta de los sectores trabajadores, al punto de considerarlos el centro de la historia futura de la humanidad, y no una simple comparsa como se los había motejado previamente. Con posterioridad a la revolución rusa, muchos grupos de vanguardia adquirieron un lenguaje y temáticas acordes a la revolución social al punto que, como ocurrió en Hungría, algunos de sus integrantes llegaron a participar activamente en los gobiernos revolucionarios. En América Latina muchas de las tendencias vanguardistas en el arte fueron conocidas, discutidas y replicadas, sin embargo sus cultores locales han sido duramente criticados por ser simples reproductoras de las tendencias europeas, al punto de afirmar que sus proyectos sociales siempre nacieron abortados (Jocelyn-Holt, 1997: 54).

Este artículo propone una mirada diferente, particularmente se centrará en las relaciones entabladas por un grupo de artistas chilenos y un exiliado del fallido gobierno socialista de Bela Kun en Hungría, en el puerto de Valparaíso entre 1922 y 1923, que significó la creación del grupo Rosa Náutica. Este grupo ha sido muchas veces estudiado por los círculos académicos desde su manifiesto, el que es descrito como una burda reproducción de las tendencias en boga en Europa (Yurkievich, 1968; Verani, 1995; Subercaseaux, 2004; Schwartz, 2006), no abordándose los textos posteriores que elaboraron, orientados a profundizar en nuevas comprensiones de los sectores de trabajadores desde sus experiencias cotidianas. La literatura creada en esos años, particularmente por Zsigmond Remenyik y Julio Walton, reflejó un giro hacia un conocimiento pleno del cotidiano de Valparaíso, sin discursos moralizantes, donde autores y personajes se funden en una misma experiencia y lenguaje. Esos textos constituyen una experiencia singular tanto para Chile como para el continente en su conjunto, como afirmó Schwartz (2006: 100), situación 
extrapolable también al grupo en sí, donde la influencia no fue unidireccional, registrándose diálogos e influencias americanas en los grupos vanguardistas centro-europeos.

El objetivo de este artículo es mostrar las relaciones artísticas y políticas que se generaron dentro del grupo vanguardista Rosa Náutica de Valparaíso, explicitar cómo ellos fueron capaces de crear una literatura que no solamente reconociera el cotidiano de los sectores que habitaban los cerros del puerto sino, además, convertir sus escritos en manifiestos sobre porqué los sectores de desposeídos debían reemplazar a los grupos de intelectuales y políticos en la conducción de la revolución social, que lo autores consideraban inminente. Para llevar a buen término nuestra propuesta hemos dividido el artículo en 3 apartados, cada uno con su particular discusión bibliográfica, teórica y temática: primero una presentación general del contexto político y artístico de Hungría, ahondando en la experiencia de las vanguardias artísticas que participaron del gobierno socialista de Bela Kun y su posterior exilio ; segundo, se realiza una exposición del ambiente artístico en Chile, apuntando especialmente a las formas de representación del mundo popular urbano que utilizaba la literatura de la época; y el tercer apartado ahonda en el contexto social de Valparaíso en la década de 1920, cómo se gestó el grupo Rosa Náutica y por cuáles medios se llegó a la búsqueda de representar el cotidiano porteño como motivo central de sus obras.

\section{Presentación del contexto político y artístico de Hungría}

Para comprender la estética y simbolismo del grupo Rosa Náutica es central abordar las experiencias históricas europeas donde se gestaron, la utilización del formato póster o la simbólica del lamparero por la vanguardia de Valparaíso remiten a su origen en Hungría. Siendo central comprenderlos históricamente desde su matriz para, con posterioridad, analizar su resignificación en Chile. Corresponde iniciar con la coyuntura central para el mundo artístico occidental de principios del siglo XX, la primera guerra mundial.

El inicio de la guerra, en 1914, hizo que gran parte de la intelectualidad húngara volcara sus discursos hacia un nacionalismo bélico, sin embargo artistas, como Lajos Kassák, rechazaron tales posturas al afirmar que era indisociable la vanguardia artística del compromiso social. Fundando la revista Hoy (Ma) para difundir sus ideas y las de sus cercanos (autonombrados, Activistas). La figura de Kassák fue medular en el desarrollo de las vanguardias húngaras, ya sea en su rol editorial, por representar un nuevo perfil de artista (ya que no provenía ni de las clases acomodadas o medias, sino de los estratos populares, ejerciendo labores de herrero inclusive durante sus períodos de artista reconocido) y, además, por reconocer y dar difusión a nuevas formas de expresión pictórica que superaban el uso de murales o telas como soporte —desde 1916 Kassák realizó sus obras en el formato de poster, las cuales incluían sus propios manifiestos artísticos y políticos, y que eran instaladas en las vías públicas de Budapest. En su período dirigiendo Hoy fue acompañado por grabadores que también adherían al 'arte del poster' como soporte de sus trabajos, cuales fueron Sándor Bortnyik, Béla Vitz y János Mattis-Teutsch (Remenyi, 1951: 120; Mansbach, 1990: 10-11). 
Hacia 1918 ya la guerra veía su término y con ella las tensiones sociales contenidas afloraron como revolución política contra el Imperio, produciéndose la dimisión del rey Carlos I de Austria y la formación de un gobierno de transición (Remenyi, 1944: 88). La debilidad del nuevo gobierno fue aprovechada por el Partido Social Demócrata y el recientemente creado Partido Comunista, quienes gestaron un golpe de estado que situó al dirigente comunista Bela Kun a cargo del gobierno, el 21 de mayo de 1919 (Pastor, 1989: 89-90). Los Activistas de Kassák apoyaron activamente al gobierno de Kun, obteniendo en las primeras semanas una favorable recepción del régimen, que los invitó a definir la cultura y las artes bajo el 'nuevo socialismo'. Esta cordial relación se quebró cuando Kassák condenó las políticas artísticas del régimen de Kun (orientadas a igualarse con el arte proletario de la Rusia bolchevique), siendo la respuesta gubernamental el cierre de la revista Hoy. No obstante lo anterior, la gran mayoría del grupo de vanguardia permaneció fiel al gobierno de Kun (Mansbach, 1990:11-12).

Esta fractura entre Kassák y Kun fue una más dentro de un gobierno que se dividía en facciones, atomizando su poder y volviéndose poroso a la reacción monárquica. Muestra de lo anterior es que a poco más de tres meses de instaurado, tuvo que entregar pacíficamente el gobierno a las fuerzas militares imperiales que entraron en Budapest el primero de agosto de 1919. La instalación de una regencia militar significó la prisión y posterior exilio de gran número de intelectuales, que en su mayoría optaron por la ciudad de Viena como su nuevo hogar (Chase, 2008: 460).

En Viena los exiliados se enfrentaron a diversas disensiones, particularmente por la difusión de nuevos movimientos vanguardistas (como Dadá) que llamaban a una revolución psicológica, por sobre la proletaria (Huelsenbeck, 1992). En respuesta Sándor Bortnyik rechazaba la 'tecnomanía' de las vanguardias y llamaban a boicotear las instituciones culturales burguesas (cine, prensa, auditorios, cafés, entre otros); dando un paso más allá al expresar que los artistas de vanguardia no eran una voz de autoridad que debía ser seguida silenciosamente por los sectores proletarios, siendo, en cambio, escaso lo que los artistas tenían para enseñarles (Botar, 1993: 38 y 43).

Inmerso en las polémicas de los exiliados húngaros en Viena se encontraba el hijo de una familia de pequeños nobles, Zsigmond Remenyik, quien luego de graduarse en 1919 de bachillerato clásico (lengua y literatura latina) en el Colegio Católico de los Cistercienses de Dormànd — su ciudad natal—, abandonó todo para ir a Budapest. Ahí estableció contactos con Lajos Kassák y durante el gobierno de Bela Kun se dedicó a repartir panfletos políticos en la capital y su ciudad natal, por consiguiente con la restauración monárquica del 1920 se exilió en Viena, al igual que otros jóvenes vanguardistas (Ferdinandy, 1975: 15 y 9; Scholz, 2009: 10). En su estancia en Viena se mantuvo cerca del grupo de Bortnyik, adquiriendo una visión del arte como una expresión de la política y lo grotesco de la vida (Ferdinandy, 1975: 20-21). La pertenencia a un grupo vanguardista asociado a la extrema izquierda no mermó los duros apodos con que los exiliados se referían a él, por su nacimiento y visión de las artes (le llamaban 'el pequeño millonario de Eger' y 'el quijote de Hever'), situación que paulatinamente lo fue marginando de los 
exiliados, hasta llevarlo a la resolución de dejar Viena y viajar a las Américas, a fines de 1920 (Ferdinandy, 1975: 10; Scholz, 2009: 16).

Su viaje americano le llevó a Buenos Aires, donde pasó una temporada, y luego al puerto de Valparaíso, donde en diciembre de 1921 se integró activamente al grupo vanguardista porteño liderado por Neftalí Agrella y Julio Walton. Será en Valparaíso donde convergerán los lenguajes vanguardistas europeos con la experiencia social de los chilenos, gestándose una nueva manera de representar a los sectores de trabajadores y desposeídos dentro de la literatura chilena (Ferdinandy, 1975: 10; Scholz, 2009: 12).

\section{Visión sinóptica de los escritores sociales y vanguardistas de Chile a inicios de la década de 1920 y su mirada hacia el mundo popular}

Habitualmente no suelen relacionarse la literatura de temática social en Chile con las corrientes de vanguardia, más bien pareciera que fueran movimientos que transitaron en paralelo y en específicos momentos se imbricaron. La literatura de temática social puede considerarse una rama de la literatura chilena desde 1880, cuando los autores nacionales adquirieron una cierta sensibilidad social, producto de la rápida urbanización de las ciudades y las lecturas de los 'realistas' franceses, como Émile Zola, Honoré de Balzac, Stendhal, entre otros. ${ }^{1}$ Este grupo fue complementado con los relatos de corte testimonial que, con posterioridad a la guerra civil de 1891, representaron al mundo social (de trabajadores y sectores medios) atrapado y ahogado por un mundo político oligárquico caduco y estático frente a los tiempos - en esa línea se encontraban autores como Daniel Barros Grez, Benjamín Vicuña Subercaseaux y Alberto del Solar, entre otros (Quezada, 2001: 58-59).

Estilísticamente la literatura de temática social chilena de fines del siglo XIX aun arrastraba los resabios del romanticismo y modernismo, corrientes que los autores del nuevo siglo optaron por abandonar. Aquel proceso se inició con la publicación de 'Juana Lucero' de Augusto D'Halmar, en 1902, 'Sub terra' de Baldomero Lillo, en 1904, y la edición póstuma de la obra de Carlos Pezoa Véliz (Calgari, 2010: 23). En un sentido teórico ellos se propusieron construir una hermenéutica de la cultura de los sectores de trabajadores y pobres de la ciudad, con miras a traducir sus formas, estilos y vidas al público literario de los sectores altos, buscando trascender los llamados circuitos culturales. ${ }^{2}$ Apreciándose ejemplos como 'El roto' de Joaquín Edwards Bello, de 1920, o 'El conventillo' de José

\footnotetext{
${ }^{1}$ Uno de los primeros compiladores de esa tendencia para el público chileno fue Pedro Balmaceda Toro en "La novela social contemporánea", de 1889 . Véase Calgari, Jaime, "Recepción de la narrativa social europea en Chile (1880-1920)", Literatura y Lingüística 22, Santiago de Chile, 2010, 20-22.

${ }^{2}$ Bernardo Subercaseaux ha expuesto que a inicios del siglo XX habrían existido tres circuitos culturales: ilustrados, de masas y popular. Dando a entender que habrían convivido independientes entre sí y con pocos vasos comunicantes. Esta idea es abiertamente criticada por Hachim, quien desestima que los límites de los circuitos hayan sido tan claro para los contemporáneos y, mucho menos, que ellos eran herméticos a las influencia de los otros circuitos. Véase Hachim, Luis, Carlos Pezoa Véliz: Alma chilena de la poesía, Valparaíso, Ediciones Universitarias de Valparaíso, 2005, 11-12.
} 
Santos Vera, de 1921, que buscaron retratar sin tapujos los espacios de sociabilidad de los trabajadores, no obstante, siempre con una mirada moralizante y, a lo menos en el caso de Santos Vera, positiva hacia las proyecciones de la regeneración del pueblo y la revolución social (Pinto, 2001: 97 y 105-107; Calgari, 2010: 26).

La poesía, en tanto, representaba a los sectores de trabajadores desde un lenguaje artístico que, en algunos momentos, también compartió la mirada moralizante de la literatura. Siendo la poesía popular, llamada genéricamente Lira popular, la vertiente más difundida en el período. Ella aunque desarrollo un tono de denuncia social contra las injusticias y la desigualdad social, según Pamela Tala, contaba con un discurso político ingenuo y que no apuntaba a la confrontación social sino a la confraternidad nacional (Tala, 2011).

Dentro del espectro poético la obra de Vicente Huidobro se encontraba alejada de tal discusión, pero ya a fines de la primera guerra mundial encontramos dos grupos que han expandido su universo de influencias estilísticas, desde Huidobro hasta los movimientos vanguardistas europeos, como los futuristas y dadaístas. Tales grupos se encontraban situados en el puerto de Valparaíso y en torno a la revista Claridad, órgano de los estudiantes de la Universidad de Chile en Santiago.

Nos referiremos, en un primer término, a la revista Claridad nació en 1920 al amparo de la Federación de Estudiantes de la Universidad de Chile y se dispuso ser el medio que destruyera los prejuicios y las formas antiguas de la sociedad chilena. Con avidez juvenil informaban a sus lectores de su decepción y descontento con el cosmopolitismo previo a la primera guerra mundial, alabando, en cambio, el advenimiento de la revolución social. Desde sus primeros números fue evidente la constante apelación a la revolución de la sociedad y las artes, realizándose innumerables menciones a los movimientos europeos, al punto de crearse manifiestos propios a semejanza, o en diálogo, con sus símiles de Europa. ${ }^{3}$ El más renombrado fue el Manifiesto Agú, firmado por Martín Bunster y Alberto Rojas Giménez, bajo seudónimos, que reinterpretó las fórmulas dadaístas y llamó a los poetas a usar el grito como verdad y emoción desnuda. ${ }^{4}$

Los discursos revolucionarios llevaron a los estudiantes a adoptar nuevas formas de organización, como fue en 1921 el grupo Spartacus, adherido al soviet de estudiantes, que propugnaba en su manifiesto el completo rechazo de las artes comerciales y sus circuitos intelectuales. ${ }^{5}$ Aquel abandono del mundo cultural y artístico previo dotó de nueva vida a

\footnotetext{
${ }^{3}$ Como ejemplo, en su número 30, de 1921, publican una esquela enviada a ellos por Huidobro desde Madrid, que reproduce, en castellano, dos manifiestos Dadá firmados por Tristán Tzara y Francis Picabia. Véase "Las nuevas tendencias del arte", Claridad 3, Santiago de Chile, 26 de octubre 1920, 3.

${ }^{4}$ El Manifiesto venía acompañado con tres poemas (En horas de terror, Bar y Paisaje), que incorporaban elementos del estilo Dadá mezclados con las formas propias de la poesía de Huidobro. Véase Martín, Juan y Guimel, Zain, "Las nuevas tendencias estéticas: Agú”, Claridad 6, Santiago de Chile, 13 de noviembre 1920, 7.

${ }^{5}$ En lo medular el manifiesto expresaba: "Hasta ahora hemos vivido superditados a los intereses del capitalismo burgués, que nos estruja, nos humilla y exije de nosotros un arte nauseabundo y pastoso (...) Declaramos que nuestro ideal es revolucionario y que por tanto quedan fuera de nuestro grupo los falsos artistas,
} 
las aulas universitarias, mas carecía de representatividad y legitimidad dentro de los grupos de trabajadores de la capital y, aún menos, de sus sectores radicales.

Paralelamente en Valparaíso se comenzaba a gestar un pequeño movimiento artístico, particularmente en torno a la persona de Julio Walton Hesse. Literato, grabador y estudiante de Derecho de Viña del Mar, en la reseña biográfica que le hizo Neftalí Agrella (1999: 256-269) en 1921, relató la importante influencia que tuvo de Oscar Wilde, Anatole France y Baudelaire en su primera etapa artística. Esa etapa se vio coronado con la premiación de su obra teatral Hijo de nadie por la Federación de Estudiantes de Valparaíso, durante la Fiesta de la Primavera de 1919 (Walton, 1919; Agrella, 1999, 268). La apertura de la obra teatral, que versaba en la prohibida relación entre un estudiante de acomodada situación y una modista de baja estofa, fue realizada por un monólogo que daba cuenta de la crítica mirada social de Walton, no obstante expresada en un lenguaje tradicional y ajeno aún a las tendencias vanguardistas.

Por aquella época Walton participaba activamente en el ámbito editorial del puerto, siendo fundador de la revista Númen en 1918 junto a Alberto Moreno y Juan Egaña (Silva Castro, 1928), al término de aquella fundó y administró la Editorial Siembra en 1919, que se prolongó en una revista del mismo nombre en febrero de 1920. En su primer número vemos la publicación de un poema propio con claros atisbos de Apollinaire y los futuristas

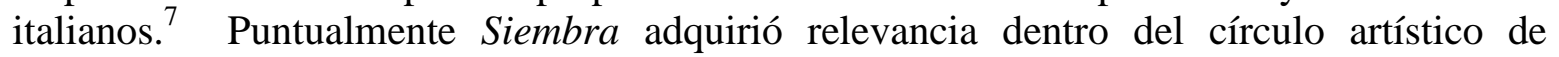
Valparaíso y Santiago, al publicar traducciones de obras de Oscar Wilde, Anatole France, Rabindranath Tagore y obras originales de Gabriela Mistral, Augusto D'Halmar, Luis Roberto Boza entre otros, siempre con informaciones sobre las vanguardias europeas, particularmente del movimiento futurista.

Acompañaba a Walton en la gestación de tales revistas el poeta de Mejillones Neftalí Agrella de la Fuente, quien posteriormente será el líder del grupo Rosa Náutica. En el número 2 de Siembra, Agrella, publicó un poema llamado "Camino inexorable" que seguía

encanallados en el arte de agradar a un público de burgueses analfabetos, agiotistas, anticuarios y políticos". En "Primer manifiesto del grupo universitario Spartacus a los artistas y estudiantes de Bellas Artes", Claridad 30, Santiago de Chile, 20 de agosto 1921.

${ }^{6}$ El monólogo parte así: "La constitución actual de la sociedad humana adolece de defectos capitales credos por ella misma; falta de comprensión, de solidaridad, de unión, son las causas determinantes de todos estos disturbios. Por otra parte el miedo atroz de los humanos a derribar los falsos ídolos, los prejuicios, los lugares comunes y las mentiras convencionales, empeoran esta situación por demás falsa" (Walton, 1919, s/n).

${ }^{7}$ El poema íntegro de Walton es: "Filigranas: De las mayorías nacen los tiranuelos / Guarda las ideas dentro de cofres herméticos dentro de tu propio corazón y sea él una urna cerrada también / No hables alto, porque si lo haces asustarás a los imbéciles / Cuando la fuerza te domine no des razones porque serán palabras lanzadas al desierto / Si quieres medrar en la vida, pertenece al grupo de los mediocres ahogando los ímpetus de tu corazón / Haced de vuestra vida un proyecto y viviréis felices. No penséis nunca en el fin, contentaos con esperar siempre; porque, en verdad, la suprema belleza no está en ellas mismas sino en el valor que nosotros les damos / Una mujer bonita no necesita perfumarse; a las orquídeas les basta con su hermosura. Walton" (Walton, 1920, s/n) 
un esquema tradicional de escritura y temática, alejado de formas vanguardistas. ${ }^{8}$ En tales años la prosa más vanguardista de Valparaíso correspondía al pinto Pedro Celedón (Brumario), quien, también en Siembra, publicó un ensayo titulado "La obsesión espantosa" que muestra un acercamiento a tópicos más oscuros, que ya dan luces del estilo futuro del grupo de Valparaíso. ${ }^{9}$

Dentro de tal universo artístico, que era Valparaíso, el año de 1921 se transformó en central, según Agrella (1925) ocurrieron dos hechos fundamentales: primero, se publicó la recopilación de Huidobro, Saisons Choisies, que, en sus palabras, "era el vértice de una época así como Horizon Carré marcó el de la anterior, la de los ensayos". Los poemas de Huidobro llevaron a Agrella a incursionar plenamente en la vanguardia, ya no solamente desde los aspectos literarios sino desde un espectro amplio del arte. Tal cual lo relató Agrella en su carta a Huidobro, en 1925:

hacen cuatro años que, junto con laborar poesía y teatro (Ballets y scénarios modernos) me dedico a prepararme intensamente para substituir en la crítica literaria de este país a gente tan ñoña y de antiguo cuño como 'Alone', Misael Correa, Mariano Latorre, Emilio Vaïsse...(se salva Donoso porque, después de todo hay que reconocer que es realmente un crítico, aunque falla a veces) (Agrella, 1925, s/n).

El compromiso militante de Agrella lo transformó en una figura en torno a la cual gravitaban los dispersos cultores de las artes vanguardistas — incluidos el húngaro Zsigmond Remenyik y el ruso Marko Smirnov. La posición central de Agrella se vio beneficiada por un segundo hecho, la separación definitiva de Walton de la Editorial y Revista Siembra, volcándole a dirigir todo su ímpetu en la gestación de un grupo puramente vanguardista en Valparaíso (Agrella, 1999: 269).

En paralelo Agrella realizaba acciones gremiales y de propaganda del arte en el puerto. Ejerció como secretario de redacción del Ateneo de Valparaíso, agrupación que funcionaba

\footnotetext{
${ }^{8}$ La parte final del poema refleja lo expuesto arriba: "Oh! déjame mil veces anularme, ignorado; pero de ninguna manera lleves a ti amarrado mi corazón, camino sin término! Camino que estas confabulado con el odio asesino de la Fatalidad: por la sola razón, camino inexorable, que aún tengo corazón" (Agrella, 1920, s/n).

${ }^{9}$ El último párrafo sirve como muestra del tono general del ensayo: "Siempre huyo de esos sitios y siempre vuelvo á ellos...¿Por qué? ¿Es la náusea de todos los siglos originada por la podredumbre que todas las cosas resuman en la soledad gris, la que sufro...? Si me parece a ratos que mi cuerpo, todos los cuerpos humanos estuviesen cubiertos por esta plumilla monstruosa de animal recién nacido...Hace poco, no más, que he empezado á experimentar esta horrible sensación...Antes las ruinas me eran gratas y aplacaban la efervescencia de mi ánimo ¿Qué es lo que me pasa? ¿Cómo curar este extraño mal que va apoderándose de mí? ¿Por qué me gusta ya, poco la Primavera con sus colores y aromas suaves y nuevos...? Sino que busco la fealdad gris, repugnante que originan el olvido de las gentes en las cosas... Acabad con todas las ruinas sin no queréis que éllas me envenenen de asco y llegue á ser un cadáver abandonado entre escombros negros cubiertos de esa pelucilla gris; con lagartos que aniden en mis vísceras y ratas voraces que roen mi corazón y en las noches llenas de clarividencia, sobre mi faz huesosa, las luciérnagas maravillosas desborden de mis cuencas negras, como lágrimas luminosas, ó como záfiros y esmeraldas, topacios y rubies de las manos cetrinas y negras de un avaro que de repente muere de un ataque cardíaco entre sus tesoros..." (Celedón, 1920, s/n).
} 
rotativamente entre el Teatro Alhambra, la Biblioteca Pública Santiago Severín y la Sociedad de Empleados Diego Barros Arana, siempre con miras a difundir la literatura y cultura (Parera, 1972). Aquí alternaba su visión vanguardista de las artes con una mirada social, confluyendo ambas vertientes en un tipo distinto de poesía, que era pensada como un reflejo desfigurado de la realidad social, despojada de los aspectos moralizantes de la denuncia social aristocrática. Visión que quiso plasmar en la Asociación de Artistas de Chile, que se formó finalmente en 1922, donde convivían artistas de distintas especialidades pero similares proyectos sociales. A su amparo se crearon ferias y talleres libres, que precedieron en una década a los talleres creados por su similar santiaguina (Flores, 1978). Es probable que fuera la acción directa de Agrella, en ámbitos sociales como artísticos, la explicación del porqué Remenyik se acercó a él y terminó por deificarlo en su obra (Scholz, 2000: 169-170).

Valparaíso como actor central en la conformación de una nueva manera de representar a los sectores desposeídos en Chile: la gestación y maduración del grupo Rosa Náutica (1922-1923)

El puerto de Valparaíso compartía con la capital del país, una sostenida crisis habitacional que fracturaba el ordenamiento urbano, estableciéndose barreras arquitectónicas que dividían a los grupos sociales y laborales. En el puerto tal división fue marcada por la geografía que estableció dos espacios de habitación, el plano y los cerros. Durante la segunda mitad del siglo XIX las habitaciones precarias circundantes al puerto comenzaron a ser desplazadas desde el plano a los cerros, tanto por la inversión vial como inmobiliaria, aquella erradicación fue justificada por las autoridades por el crecimiento comercial del puerto, la destrucción bélica en 1865 (en el marco de la guerra hispano-chilena) y los frecuentes terremotos e incendios (Edwards Bello, 1965: 134). Aquella política se plasmó en la utilización de antiguas casas como espacio de habitación múltiple, transformando a los cerros en sus quebradas en espacios de alta concentración demográfica pero escaso acceso a beneficios sociales e higiénicos.

La preocupación por los sectores populares urbanos en Chile nació hacia las últimas décadas del siglo XIX impulsada por las ciencias médicas, que temerosas de una fractura social en el país, utilizaron el higienismo como explicación para la realidad social imperante - proponiendo normas y estructuras sociales según el tipo de nacimiento, ambiente de crianza y acceso a la salud de los individuos (Molina, 2006). Derivado de aquel proceso se construyó una 'opinión pública', gestada por la prensa y el mundo político, que juzgaba y condenaba a priori a todas las personas que habitaban los sectores no urbanizado de las ciudades, realizando asociaciones libres de adjetivos cual si fueran sinónimos (por ejemplo, sucio, negro, ladrón, maleante, libertino, lacra social, entre otros). Para el caso de Valparaíso los trabajos de María Ximena Urbina (2002a y 2000b) y Lucía Valencia (1999) muestran con crudeza como se construyó un relato social, por parte de la prensa periódica, sobre cómo la diferencia entre el plan y los cerros provocaba cambios psicológicos y conductuales en sus habitantes. 
No obstante después de las huelgas de los trabajadores portuarios en Valparaíso, tanto de 1894 como 1903, y particularmente cuando la última derivó en saqueos en el plano, la autoridad municipal comenzó a desarrollar mayores y mejores inspecciones a las habitaciones comunitarias, forzando a los arrendadores a introducir mejoras en la arquitectura de las casas utilizadas para tal fin (Espinoza, 1988: 22; Grez Toso, 2000; DeShazo, 2007: 164-165). Lamentablemente gran parte de este incipiente esfuerzo fue destruido como consecuencia del terremoto de 1906, que significó la caída de edificaciones o su incendio, además de hacer que cerca de 60.000 damnificados tuvieran que vivir en carpas precarias en las principales plazas del puerto por varias semanas y meses (Urbina, 2006).

Con posterioridad al terremoto de 1906 casi la totalidad de las familias de los trabajadores manuales y portuarios se desplazaron a las cotas altas de los cerros, arrendando piezas en los conventillos locales o construyendo habitaciones con productos de desecho (Urbina, 2000a). La precariedad de la habitación, el hacinamiento y la lejanía de los servicios sociales e higiénicos del plano urbano hicieron que en los cerros se propagaran enfermedades como cólera, disentería, fiebre tifoidea, viruela, tifus exantemático, entre otras (Laval, 2013: 313). Siendo común que en las habitaciones más altas de los conventillos se colgaran telas blancas, indicando a los inspectores municipales y visitantes que existía un enfermo (Urbina, 2002b: 8). El ambiente infeccioso aumentó en los años posteriores al inicio de la primera guerra mundial, cuando el puerto vivió epidemias de influenza (la llamada gripe española), que llevaron a colocar en cuarentena calles y conventillos (Laval, 2013).

En este ambiente social y urbano tan cargado de tensiones como conflictos arribó Remenyik en 1921, y con una rapidez sorprendente conoció y se asoció con el grupo de Agrella (Ferdinandy, 1975, 10; Herrera, 2014, 209). El biógrafo de Remenyik, Georges Ferdinandy, describió los meses entre su arribo (diciembre) y la edición como poster del Manifiesto Rosa Naútica (marzo) como un espacio colaborativo grupal, donde se mezclaban las impresiones locales de las vanguardias con la experiencia vivencial de Remenyik, todo matizado por las diferencias de lenguaje y el aprendizaje del castellano por el activista húngaro (Ferdinandy, 1975, 39). Con la distancia del tiempo, Julio Walton recordó la vitalidad de tales años y cómo su unión, como grupo vanguardista, hizo que traspasaran la simple reproducción de las tendencias europeas. ${ }^{10}$

\footnotetext{
${ }^{10}$ Walton en el prólogo al libro de Agrella El alfarero indio, de 1933, describía así al grupo Rosa Náutica: 'La revista mencionada (Númen) y luego 'Siembra' hicieron avanzar la producción juvenil porteña hasta un término en que un nuevo espíritu - el de la post-guerra - había de tomar lo mejor, combatiendo forzosamente a lo más débil y añejo. Muchas firmas tradicionales prestigiadas se silenciaron. Nuevas firmas anónimas surgieron. Pocos pasaron el puente de los Ismos y de las tendencias nuevas. Luego se cristalizó un grupo, propiamente porteño, que sufrió la repulsa obcecada de los que se habían quedado atrás. Agrella fue el 'alma máter' de ese grupo, en mi compañía. Una interesante labor y gesta renovadora realizamos [...] Proyectamos la primera antología de la poesía nueva. Se hicieron veladas teatrales, etc. Fue un movimiento completo, que repercutió en la juventud de Santiago, incitándola a luchar por una renovación literaria, durando nuestro movimiento hasta 1925" (Agrella, 1999, 180-181).
} 
La primera acción concertada de este grupo fue la creación de la editorial Tour Eiffel según Yurkievich $(1968,652)$ su título era un guiño directo a la obra de Huidobro-, desde la cual proyectaban una serie de publicaciones en formato libro y poster. El manifiesto era la puesta en escena de un grupo juvenil que intentaba diferenciarse absolutamente del medio artístico chileno. Por lo mismo sus frases más sardónicas fueron dirigidas a los críticos renombrados y su ceguera frente al avance de las nuevas formas artísticas, al igual que para los artistas cómodamente acostumbrados al aplauso de las camarillas. ${ }^{11}$. Probablemente el debate más importante que ha suscitado este manifiesto nació de la controversia sobre la autoría del mismo. Lázsló Scholz (2000) ha apostado por afirmar que el manifiesto fue gestado bajo el alero de Zsigmond Remenyik - en gran medida por algunas faltas menores de ortografía y la referencia directa a las tendencias futuristas-, opción que ha sido polemizada por Adolfo de Nordenflycht (2011: 122) quien consideró que la figura de Neftalí Agrella era el cerebro tras el manifiesto. Sin documentación de primera mano es complejo cerrar tajantemente esta discusión, mas consideramos como fundamental para dilucidarla la carta escrita por Agrella a Huidobro en 1925 (citada previamente), ya que en ella se repiten muchos de los argumentos aparecidos en el manifiesto, además devela que Agrella era un conocedor de las tendencias ultraístas, creacionistas y futuristas. La comparación entre el manifiesto y la carta citada muestra una directa consonancia entre los estilos de escritura, en forma y fondo, siendo plausible afirmar que la redacción del manifiesto recayó en Agrella más que en Remenyik.

Pudiendo afirmarse que la influencia de Remenyik se redujo a dos elementos, el uso del formato póster y la inclusión de un grabado. El uso del poster conllevaba un desdén por los espacios canónicos de discusión artística y un enfrentamiento con el público no preparado al arte de vanguardia. Era, en muchos sentidos, romper con la mediación de la crítica artística y avanzar al diálogo directo entre autor y espectador. Estilísticamente el manifiesto se destaca por la inclusión del grabado Activismo (Aktivizmus) del húngaro Sándor Bortnik que, según Scholz (2009, 12-13), trajo Remenyik desde Viena.

En párrafos anteriores hablamos de debate, aunque en gran medida no ha habido un verdadero debate en torno al manifiesto. No obstante ser varias veces reproducido (Yurkievich, 1968; Schwartz, 2006; Verani, 2006; Remenyik, 2009) habitualmente ha sido caracterizado como una expresión 'interesante' pero infecunda, siendo presentada por algunos autores, como Verani (2006: 39) o Subercaseaux (2004: 165), como una chiquillada. Diferimos en este caso, ya que consideramos que fue la primera expresión de un grupo artístico que venía consolidando su visión crítica sobre el arte chileno desde los tiempos de Númen y Siembra, donde el manifiesto no fue un punto de inicio o término sino,

\footnotetext{
11 Así el manifiesto habló de 'críticos esquimales', dignos de la 'Laponia espiritual' que era el Chile de la década de 1920. En tanto para los literatos de renombre no suavizaba sus calificativos: 'Los viejos 'poetas', en sus sillones valetudinarios, harían bien en saludarnos agitando las banderas grises de los sus manos. Ellos y todos los que viven en la actualidad de hace 50 años, deberán abrir la ventanillas de sus desvanes psicológicos, para vernos, a nosotros, que vivimos en la actualidad futura" (Remenyik, 2009, 22).
} 
más bien, un hito definitorio de su opción artística; además de consolidar el liderazgo de Agrella dentro del grupo.

Con posterioridad a la publicación del cartel-manifiesto, la editorial Tour Eiffel publicó la obra La Tentación de los Asesinos, "fuerte narración, neo-realista del escritor activista húngaro Zsigmond Remenyik, errante por América del sur, libro del cual no se vendió un ejemplar en las librerías", según lo recordó Walton en 1933 (Agrella, 1999: 181). Scholz (1991, 75) dijo que el poema fue escrito en 1921, en Valparaíso, y que estilísticamente difería de todo lo escrito en el período en América del sur. Temáticamente se presenta como la visión de un nuevo Zaratustra nietzscheano que vive para refundar el orden social e iluminar al mundo con las linternas de las revoluciones sociales y artísticas. ${ }^{12}$

Es posible considerar al Manifiesto Rosa Naútica y La tentación de los asesinos como productos 'tradicionales' del lenguaje vanguardista europeo de la época, empero las siguientes dos obras de Remenyik en Valparaíso salen completamente del marco vanguardista vienés de su autor, nos referimos a La Angustia! y Los Muertos de la mañana (Ferdinandy, 1975, 53). Este giro no podemos únicamente considerarlo desde el plano estilístico sino, también, como un impacto de las reflexiones de Agrella y Walton sobre el mundo social de Valparaíso. En aquel sentido La Angustia! describe directamente la vida en los conventillos y el mundo prostibulario, Ferdinandy $(1975,52)$ afirmó que en esta obra Remenyik comenzó a apropiarse de Valparaíso y su vocablo popular, olvidando el cuidado lenguaje de los manifiestos. ${ }^{13}$

${ }^{12}$ El canto 12 contiene todos los elementos mencionados, por lo mismo lo citaremos en extenso: "Luego se levantó / y abrió las puertas de las ciudades, rompió las chimeneas de las fábricas y arebataba los barrios! / Salió el sol tras de las montañas: / Entonces huían de las fábricas y barrios los miserables! Los trabajadores con sus manos rotas y los niños pequeños llorando de hambre y las hijas de la noche! / y ellos temblando le preguntaban: / Oh, di qué quieres? / y él por contestación arrebataba los palacios de los ricos también. Las campanas de los campanarios tiro a las aguas del mar, y sacó los dos cuchillos de sus ojos, / y hablaba así: / Yo soy el asesino, y el dios está sentado arriba de mis palmas. Yo conozco los secretos de la naturaleza, tengo mi cuerpo de la materia del sol, la luna y las estrellas! Mi padre era un sepulturero y mi madre tuvo la señal de los mártires! Mi leche tuvieron los cadáveres de los ahorcados y cuando ví la materia gastada sabía que la naturaleza hay que cambiar, porque tuve la fuerza de los lobos! / Buscad la libertad! / y ellos lloraban / gritando! / Los trabajadores rompieron sus instrumentos sangrientos / y las hijas de la noche lavaban sus caras en lágrimas de los niños inocentes!" (Remenyik, 2009, 40). Hemos mantenido el castellano chapucero de Remenyik, ya que el mismo se vuelve casi un personaje más en todas sus obras.

${ }^{13}$ Para graficar lo anterior reproduciremos íntegramente el canto 4: "La niebla cayó! / las campanas repican en la niebla espantosamente! Algunos marineros del puerto andan vagando a travez de las avenidas muertas / con antorchas lacres en sus manos! / todas las ventanas están abiertaz / parecen ojos ciegos en la noche! / y el mar / levantándose en un temporal! / los ladrones! / en el fondo de un callejón! Los marineros borrachos de antorchas lacres en sus manos / suben por los pasajes de los cerros! / una mujer gorda se aparece bajo las puertas, sonriendo y dice a los borrachos: / tengo una virgen vale 7 oros! Ahora no anda nadie por la calle ¡cayó la niebla, venid! / y ante las antorchas lacres levantan las cortinas oscuras de la oscuridad! / CUARTO! La niña! Los marineros cuelgan las antorchas en la pared! / quereís tomar algo? / aguardiente! / y la mujer cierra las puertás de la calle! / ahora no anda nadie afuera, la niebla cayó! La niebla cayó! / baile! / vale 7 oros? / mujer cierra las puertas del cuarto! Toman! La niña gritando lleva a los borrachos a un rincón! / la mujer cierra las ventanas también! / no hay nadie? / nadie!! / los borrachos cuelgan sus vestidos bajo las antorchas lacres y bailan así! / la niña grita, / qué queréis? / en la ciudad repican las campanas espantosamente! 
Dos elementos podemos destacar de su afirmación, primero el grupo Rosa Náutica nunca intervino la escritura fonética de Remenyik e inclusive la incentivo, si seguimos a Schwartz (2013), ya que el 'hombre nuevo' no podía encapsularse en las normas del lenguaje y su rol era el rescatar la oralidad para la escritura. A lo anterior podemos agregar algo más, a diferencia de otros autores que han retratado a los habitantes de los conventillos — gran parte de ellos compilados y analizados por Marco Antonio León (1995)_, ellos siempre se diferencian del hablante, al cual lo presentan hablando con modos populares, en tanto para sí reservan los cánones formales del castellano. Esa situación no ocurre con Remenyik, quien escribe al igual como hablan sus personajes, no se disocia como autor. Eso nos lleva al segundo punto: a diferencia de las obras anteriores aquí no hay un discurso renovador o reivindicativo, es una presentación simbólica de la vida de los cerros de Valparaíso (relato del que es parte del autor), es una cruda representación que nunca apela a ningún tipo de revolución social (a diferencia de La Tentación de los asesinos), más bien se propone retratar el fenómeno de la pobreza de los cerros, siendo la obra un medio de difusión del cotidiano de los individuos y no un vehículo para la exposición del autor -aquí consideramos que se puede una conjunción entre los postulados vieneses de Bortnyik, mencionados previamente, y las ideas de Walton sobre los matices de la pobreza en el cotidiano de Valparaíso.

Los muertos de la mañana se abre a una nueva experiencia literaria, centrada en los desamores de una pareja de un conventillo durante una epidemia en el puerto, en ella aparecen los habitantes del conventillo como un coro griego que interpela a los protagonistas y, además, recela y condena los actuares de la mujer por considerarlos impúdicos hacia el hombre y la pobreza generalizada. ${ }^{14}$ Aquel control social ejercido por la comunidad sobre la mujer aparentemente fue una constante dentro del Chile popular de la época, como refirió en su momento Luis Alberto Romero (1997: 135-136), pero dentro del relato de Remenyik fue el delito 'social' de la mujer (dar la espalda a sus pares de clase) el detonante de la aparición de la 'peste' en el puerto, acabando por ser la muerte de la mujer necesaria para poner fin a este drama. ${ }^{15}$

Y la mujer cierra las claraboyas del techo! / los borrachos sacan sus ropas sucias, y las cuelgan sobre las antorchas lacres! / oh, por dios, / por dios, / DIOS! / el callejón se hinca de rodillas ante el puerto de la ciudad en la niebla" (Remenyik, 2009, 51-52).

${ }^{14}$ Citaremos una sección del canto 4: “A penas se acostaron bajo las velas acules de la miseria, / las paredes abrieron sus estómagos, las entanas se cayeron por dentro de la pieza y el techo se levantba hacia el cielo; / y con gritos espantosos aparecieron los habitantes del convetillo en sus trajes de noche, / entre las ruinas de las paredes y de las ventanas y puertas; / y ella, / con sus tetas sobre la cabeza del cojo: / qué sucedió? Qué? Qué? / y ellos gritaban continuamente, mostrando con las manos a ella: / la hembra; la hembra; la amante de toda la calle; ella; todas las noches como tu quedas dormido, ella se vái a donde se vá? Duerme junto con tu amoi con el gordo de la panadería; y se sienta sobre las colinas de pan; y nosotros; en la miseriaj en la miseria ella todos; todos por ella no mási” (Remenyik, 2009, 67).

${ }^{15}$ El canto 5 dice: "y ellos abrieron las ventanas de sus piezas, / y las puertas grandes del conventillo como un coro trágico gritaban hacia el cojo: / a donde se fue ella? A donde? Cuando tu dormiste, ella abrió las puertas de la pesadilla, y salió por la calle? A donde se fue / nosotros la hemos visto, ved, la peste están sentada sobre la ciudad, la peste / LA PESTE / todos los barcos de la bahia son infestados y ese conventillo tambien / a donde se fue ella? A donde? Ella tiene un amante de cinco ojos verdes, quien duerme en la morgue/ / EN LA 
La representación artística de Valparaíso por Remenyik fue contestada por Julio Walton, gestándose un diálogo entre ellos donde fue posible ver cómo se fundía el lenguaje de las vanguardias con las experiencias e imágenes de los sectores de trabajadores. En el caso de Walton, se propuso retratar la dualidad de los barrios rojos de Valparaíso, mostrando la alegría desatada como la miseria moral y sentimental que escondía la fiesta (Nordenflycht, 2011: 126). Aunque permaneció inédito hasta hace poco, El aullido de las Rameras, firmado en agosto de 1922, propone una clara secuencia entre el manifiesto Rosa Náutica y su escrito, agregando actores y circunstancias propias del cotidiano porteño, buscando avanzar (al igual que Remenyik) en una caracterización más fidedigna de la experiencia de vida de los sectores desposeídos de Valparaíso, superando el simple culto al feísmo que le achacó Scholz $(1991,76)$ al escrito de Walton. ${ }^{16}$

La búsqueda colectiva del grupo Rosa Náutica por avanzar en las artes de vanguardia, no sólo en el plano temático sino también de compromiso social con los 'pobres de la ciudad' permaneció, aun cuando, Remenyik partió al Perú a fines de 1922. En Lima publicó su obra Las tres tragedias del lamparero alucinado, que recopilaba La tentación de los asesinos, La Angustia y Los muertos de la mañana, que en reediciones posteriores les fueron adosadas reproducciones de carteles-poster que habrían acompañado originalmente a las obras. En estos últimos se encuentran los más claros manifiestos del autor húngaro sobre el arte, la revolución social y los sujetos que deberían llevarla a cabo. En ellos criticaba duramente a los intelectuales que intentaban guiar las revoluciones futuras, afirmando, en cambio, que tanto en la revolución social como en la artística, habrían de ser los grupos de desposeídos los principales impulsores - reminiscencia directa de la visión de Agrella, cómo el mismo relataría en sus futuros trabajos. ${ }^{17}$

MORGUE / ara allá se fue / para allá/ a su amante de cinco ojos verdes se llaman lobo/ LOBO/ ya todos vamos a morir/ la peste esta sentada en la cumbre de los cerros: ved/ y as calles/ las calles parecen ataudes abiertos/ ved/ oh/ oh/ oh/ vete para allái por la morgue/ mátala, y vá a salir todo lo que sufrimos nosotros, y que sufre tu tambien/ por la morgue i por la MORGUE/ y el cojo abrió/ las cañerías/ de la tragedia/" (Remenyik, 2009, 69)

${ }^{16}$ Como ejemplo citaremos el canto 7: "LODO / los barrancones vestidos de fiesta dan sus banderolas de papel al viento Sur / pegadas a los bancos de palo 30 rameras llenan un tonel sin fondo, con esperanzas / un recién latido late en sus sienes y les hace vibrar las tetas colgantes / un gañan endomingado ha roto las amarras y brinca al són de la vihuelas sus ansias lujuriosas / las manos rebolan en las nalgas y los muslos de las rameras / $30^{\circ}$ bajo cero hay en sus / corazones entristecidos / Se pintan los rostros con betún / y en la loca zarabanda dan sus piernas, como banderolas de papel, al viento Sur. / En la ciudad pestañean / miles de ojos fosforescentes / De vuelta / en los caminos / se destrozan las manos los gañanes / y en las voces cascadas y aguardentosas de las rameras el trágico aullido / ¡aú! ¡aú! ¡aú! / resuena mohosamente" (Scholz, 1991, 81-82). ${ }^{17}$ El Cartel V afirmaba que: "Llegaré aun vez hasta el punto cuando yo diré / no es necesario el / arte! / voi a negar la utilidad de la literatura! Y mandaré todos los literatos y artistas para la mierda! / vivir la vida es el arte real! Los cojos, ciegos, mudos y sordos y otra junta de los miserables humanos / que no sirven para nada pensaron en hacer una concurrencia para la fuerza pura y cruda y salvaje, y invencible! / prefiero un boxeador negro / con su musculatura de (...) / mil veces ante / que a un intelectual! / reconosco un derecho! / el derecho a la fuerza! / el derecho de la ciencia, / lo del arte, y / lo del pensamiento / no elite!” (Remenyik, 2009, 89). 
La muerte de su pareja peruana y su pequeña hija hicieron que Remenyik decidiera cortar todos los lazos con América del Sur, retornando a Hungría en 1926. Su afiliación al antiguo régimen de Bela Kun no fue obviada por la policía húngara por lo que fue vigilado, especialmente por su cercanía con otros retornados de Viena (como eran Kassák y Bortnyik). Dentro de los grupos de retornados Remenyik aparecía como el más atípico, al punto que decidió continuar escribiendo en 'americano' —Ferdinandy $(1975,30)$ lo define así porque va mucho más allá del uso del castellano, al pretender incorporar los ritmos de la conversación hablada al lenguaje escrito-, realizando reseñas de autores hispano parlantes en revistas de vanguardia en Hungría y terminando por decidirse a escribir una novela íntegramente en castellano, terminando en 1929: Los Juicios del Dios Agrella. La novela se propone una ficticia biografía del grupo Rosa Náutica y del Valparaíso de la época, aunque la figura de Agrella domina la segunda parte del escrito - confirmando la centralidad de su figura dentro de la vanguardia porteña, tal cual otros autores han mencionado, como Oreste Plath (2013: 60) — , la primera parte es, para nuestra opinión, uno de los relatos mejor logrados sobre la problemática social chilena de inicios del siglo XX, al mostrarla repulsiva e hipnótica al mismo tiempo. La novela permaneció inédita hasta 1938, en parte por el período de tres años de prisión que vivió Remenyik por difamar a la Iglesia e incitar a la revolución en sus escritos, cuando fue editada abreviadamente bajo el título Agrella emléke (La memoria de Agrella, posteriormente titulada en Francia, El regalo de Agrella). Aquella novela terminó por ser definitiva para Remenyik ya que la crítica literaria atacó su uso del lenguaje, aduciendo que no era propio del hablar húngaro y que resonaba en el texto una melodía, un sonsonete, propio del hablar hispano que no correspondería con el canon local, inclusive el vanguardista (Ferdinandy, 1975: 31). El advenimiento de una Hungría socialista luego de la segunda guerra mundial tampoco favoreció a Remenyik, quien solamente al fin de su vida, y con posterioridad a la muerte de Stalin, vio el reconocimiento de su obra y la influencia original que provocó en los autores húngaros.

El resto de los integrantes del grupo Rosa Náutica permanecieron en Valparaíso, continuaron realizando presentaciones teatrales, musicales y literarias, pero, en definitiva, la carencia de reconocimiento artístico y social de sus trabajos gatilló su separación en 1925. Walton recordaba en 1933 este quiebre: "Pero toda esta juventud, sin embargo, no persistió. Sólo Agrella, el que escribe y algún otro, continuamos, hasta venirnos a Santiago, por razones vitales" (Agrella, 1999: 181). En un tono similar, ahora Agrella, en su obra La Muerte de los amantes, lamentando la pérdida de su compromiso social, ya sea por incomprensión pública o decepción personal:

Mis compañeros siempre soñaron con hacer su obra. Pero pasaron sin dejar mayor recuerdo que en mi vida. Vagaban ellos sin cesar, admirando las cosas profundas y lejanas. Dejaron de plasmar en una obra de arte sus odios y alegrías, sus grandes sueños y pequeñas miserias. Fueron fugaces soñadores... Sin embargo, aquel mundo era mejor! Se podía soñar sin la verdad. Se amaba intensamente con emociones formidables. Era un mundo mejor. No volveremos a vivirlo. La bondad presidía las acciones. Había ardor de humanidad en toda cosa (Agrella, 1999: 219). 
Agrella en un último intento por dar vuelta su destino escribió a Huidobro proponiéndole escribir un libro de su obra, que sería publicado a costas del homenajeado — apelando aquí a la fama de autoeditor que precedía a Huidobro, como lo relató de Torre (1974: 208 y 209). La parte final de la carta da muestra, de manera sardónica, sobre el momento apremiante que vivió él en Valparaíso:

Por otra parte tengo enormes deseos de conocer a usted personalmente. Pero ya le digo, soy pobre, vivo miserablemente en mi rincón literario, escribiendo, soñando y tomando café. Podría cumplir con mi deseo de conoceros sí - junto con las revistas o lo que me envíe, supongo a vuelta del correo-, olvidara usted dentro de un sobre un billete de a $\$ 50$, por ejemplo... Pardonnez-moi cette plaisanterie! (Agrella, 1925: s/n).

Ya en Santiago los caminos de Agrella y Walton se separaron, el primero continuó ligado a la producción artística de vanguardia, pero ahora utilizando como soporte el mundo indoamericano y no las tendencias artísticas europeas (Nordenflycht, 2011: 123); en tanto Walton estableció una librería y editorial, desde donde continuó difundiendo y editando diferentes escritos políticos de corte radical y socialista, siendo el principal editor de los escritos políticos y ensayísticos de Vicente Huidobro en Chile. Años después el escritor y político Volodia Teitelboim recordaba con tierna devoción el rol jugado por la librería de Walton, y su dueño, al cobijar a los jóvenes intelectuales de izquierda de la capital. ${ }^{18}$

\section{Conclusiones}

Este trabajo se propuso describir la propuesta artística y política del movimiento vanguardista Rosa Náutica, que se mantuvo activo en el puerto chileno de Valparaíso entre 1922 y 1923, abocándonos particularmente en su idea de reconstruir el cotidiano de la población de los cerros. Aunque puede argumentarse que sus productos fueron escasamente divulgados y pasaron desadvertidos para la crítica artística de la época, no puede desconocerse que a nivel personal influenció a los participantes del grupo y condicionó sus posteriores obras, que sí tuvieron difusión e impacto dentro de los círculos artísticos y sociales - ya sea a nivel intelectual, como ocurrió con Remenyik en Hungría, o a nivel interpersonal, como pasó con Walton y su librería en Santiago. En definitiva, el esfuerzo que hizo este grupo por reconstruir el cotidiano de los pobladores de los cerros de Valparaíso (desde el lenguaje vanguardista en boga) se adelantó en más de una década a los escritores sociales de mediados del siglo XX chileno (la llamada Generación del 38).

\footnotetext{
${ }^{18}$ En su biografía a Huidobro, Teitelboim (1996: 181) recordaba así la librería Walton en 1933: “A la hora del atardecer solíamos encontrarnos en la vieja casa de un piso, en la segunda cuadra de la calle Teatinos, tal vez al medio donde hoy alzan sus fachadas de rasca cielos el Ministerio de Hacienda y el Hotel Carrera. Pertenecía a un porteño con cara de gringo jovial y bondadoso, Julio Walton, poeta revolucionario. Soñaba con ser editor. Comenzó a publicar pequeños libros de autores chilenos, módicos folletos con temas políticos y sociales, a cargo de Gregorio Guerra [...] La familia Walton era acogedora y hacía muy gratas las reuniones, ciclos de conferencias que se ofrecían en el pequeño hall embaldosado de entrada, a una cuadra de la Moneda. Aquello para nosotros era como plantar la enseña de la rebeldía frente al palacio del poder".
} 
Recordemos que antes del grupo Rosa Náutica los sectores de desposeídos de la ciudad y campos eran representados en la literatura como individuos unidimensionales, sin profundidad, movidos únicamente por sentimientos fuertes y llevados a extremos (amor, odio, venganza, maldad, degeneración moral, ociosidad, entre otros), sin embargo en la representación del grupo se ve un cotidiano desembarazado de tales sentimientos fuertes, más bien conducido por la rutina, el agobio laboral y las diferencias sociales. Presentando a los sectores de desposeídos como personas guiadas por 'contextos sociales' y no por instintos, dando coherencia a su propuesta política que apelaba a la superación de los contextos sociales vía la revolución social. En este punto es singular e importante dentro de la escena artística chilena de la década de 1920, particularmente la que sirvió de antecedente a los novelistas sociales de la Generación del 38 (y el compromiso política de parte de ellos), investigaciones posteriores serán las llamadas a calificar y medir si existieron vasos comunicantes que nos permitan hablar de una proyección de estos esfuerzos en los autores posteriores o afianzar su carácter de movimiento autónomo y particular en las artes nacionales.

\section{Bibliografía}

\section{Fuentes impresas}

"Las nuevas tendencias del arte", Claridad 3, Santiago de Chile, 26 de octubre 1920, 3.

"Primer manifiesto del grupo universitario Spartacus a los artistas y estudiantes de Bellas Artes", Claridad 30, Santiago de Chile, 20 de agosto 1921.

Agrella, Neftalí, "Camino inexorable", Siembra 2, Valparaíso, 1920, s/n.

Agrella, Neftalí, Espiral de humo en el infinito, Antofagasta, Universidad Católica del Norte, 1999.

Botar, Oliver, "From the Avant-Garde to 'Proletarian Art': The emigré Hungarian Journal Egység and Akasztott Ember, 1922-1923", Art Journal 52:2, Illinois, 1993, 34-45.

Calgari, Jaime, "Recepción de la narrativa social europea en Chile (1880-1920)", Literatura y Lingüística 22, Santiago de Chile, 2010, 20-22.

Celedón, Pedro, "Obsesión espantosa”, Siembra 3, Valparaíso, 1920, 42-43.

Chase, William, "Microhistory and Mass repression: politics, personalities, and revenge in the fall of Béla Kun", Russian Review 67:3, Kansas, 2008, 454-483.

DeShazo, Peter, Trabajadores urbanos y sindicatos en Chile: 1902-1927, Santiago de Chile, Dibam, 2007.

Edwards Bello, Joaquín, El bombardeo de Valparaíso y su época, Santiago de Chile, Empresa Editora Zig-Zag, 1965.

Fenyo, Mario, "Writers in Politics: the role of Nyugat in Hungary, 1908-19", Journal of Contemporary History 11, Cambridge, 1976, 185-198.

Ferdinandy, Georges, L'Oeuvre Hispanoaméricaine de Zsigmond Remenyik, La Haya, Mouton Editores, 1975.

Flores, Julio, Valparaíso cultural y artístico, Valparaíso, Ilustre Municipalidad de Valparaíso, 1978. Hachim, Luis, Carlos Pezoa Véliz: Alma chilena de la poesía, Valparaíso, Ediciones Universitarias de Valparaíso, 2005.

Herrera, Hugo, "Próximo a publicarse. Sobre los paratextos sin texto de la vanguardia de Valparaíso (vestigio y especulación)", Nibaldo Acero, Jorge Cáceres y Hugo Herrera (eds.), Vestigio y 
especulación. Textos anunciados, inacabados y perdidos de la literatura chilena, Santiago de Chile, Chancacazo publicaciones ltda., 2014.

Huelsenbeck, Richard, "Almanaque Dadá. Editado por Richard Huelsenbeck por encargo de la Oficina Central del Movimiento Dadá Alemán. Berlín, 1920”, Richard Huelsenbeck (ed.), Almanaque Dadá, Madrid, Editorial Tecnos, 1992.

Laval, Enrique, "Epidemia de tifus exantemático en Chile (1932-1939)", Revista chilena de infectología 30:3, Santiago de Chile, 2013, 313-316.

León, Marco Antonio, "En torno a una pequeña ciudad de pobres. La realidad del conventillo en la literatura social chilena 1900-1940", Mapocho 37, Santiago de Chile, 1995, 113-133.

Mansbach, Steven A., "Confrontation and accommodation in the Hungarian Avant-Garde", ArtJournal 49:1, Nueva York, 9-20.

Martín, Juan y Guimel, Zain, "Las nuevas tendencias estéticas: Agú", Claridad 6, Santiago de Chile, 13 de noviembre 1920, 7.

Molina, Carlos, "La cuestión social y la opinión de la elite médica. Chile: 1880-1890", Anales chilenos de la historia de la medicina 16, Santiago de Chile, 2006, 17-31.

Muñoz, Luis y Oelker, Dieter, Diccionario de movimientos y grupos literarios chilenos, Concepción, Editorial Universidad de Concepción, 1993.

Nordenflycht, Adolfo de, "La vanguardia de Valparaíso: expresionismo de/en la periferia", Estudios Filológicos 47, Valdivia, 2011, 115-131.

Parera, Modesto, La poesía en Valparaíso, Valparaíso, Asociación Escritores de Valparaíso, 1972.

Pastor, Peter, "Recent Hungarian publications on Bela Kun", Slavic Review, 48:1, Wisconsin, 1989, 89-96.

Pinto, Jorge, "La crisis del 900 y la literatura de la época. Un análisis desde la historia", Guillermo Bravo y Jorge Pinto (eds.), Chile, 1880-1930. Literatura e historia social, Santiago de Chile, Editorial Universidad Metropolitana de Ciencias de la Educación, 2001.

Plath, Oreste, "Nefatalí Agrella. Nefatalí Fructuoso de la Fuente y Agrella, 1898", Neftalí Agrella, El astrónomo loco y otros cuentos, Antofagasta, Centro Cultural de Mejillones, 2013.

Quezada, Jaime, "La novela chilena frente a la cuestión social 1880-1930. Notas para un estudio", Guillermo Bravo y Jorge Pinto (eds.), Chile, 1880-1930. Literatura e historia social, Santiago de Chile, Editorial Universidad Metropolitana de Ciencias de la Educación, 2001.

Remenyi, Joseph, "Endre Ady, Hungary's apocalyptic poet (1877-1919)", Slavonic and East European Review. American Series 3:1, EEUU, 1944, 84-105.

Remenyi, Joseph, "Lajos Kassák, Hungarian 'Avant-Garde' writer and poet", The Modern Language Journal 35:2, EEUU, 1951, 119-123.

Romero, Luis Alberto, ¿Qué hacer con los pobres? Elite y sectores populares en Santiago de Chile 1840-1895, Buenos Aires, Editorial Sudamericana, 1997.

Scholz, László, "Julio Walton H.: El aullido de las rameras (un texto inédito del grupo 'Rosa Náutica')", Hispanoamérica 60, EEUU, 1991, 73-84.

Scholz, Lászlo, "Prólogo", Zsigmond Remenyik, El lamparero alucinado, Madrid, Editorial Iberoamericana, 2009.

Scholz, László, "Historia y ficción en 'Los juicios del dios Agrella' de Zsigmond Remenyik", Ensayos sobre la modernidad literaria, Murcia, Editorial Universidad de Murcia, 2000.

Schwartz, Jorge, "Lenguajes utópicos. 'Nuestra ortografía Bangwardista': tradición y ruptura en los proyectos lingüísticos de los años veinte”, Ana Pizarro (ed.), América Latina: palabra, literatura y cultura, Santiago de Chile, Editorial Universidad Alberto Hurtado, 2013.

Schwartz, Jorge, Las vanguardias latinoamericanas. Textos programáticos y críticos, México DF, FCE, 2006. 
Simón Marchán, "Prólogo", Richard Huelsenbeck (ed.), Almanaque Dadá, Madrid, Editorial Tecnos, 1992.

Subercaseaux, Bernardo, Historia de las ideas y de la cultura en Chile. Tomo III El centenario y las vanguardias, Santiago de Chile, Editorial Universitaria, 2004.

Tala, Pamela, "La ambivalente representación del roto en la poesía popular chilena", Estudios Filológicos 48, Valdivia, 2011, 119-132.

Teitelboim, Volodia, Huidobro la marcha infinita, Santiago de Chile, Editorial Sudamericana, 1996.

Torre, Guillermo de, Historia de las literaturas de vanguardia Vol. III, Madrid, Editorial Guadarraca, 1974.

Urbina, María Ximena, "El impacto del terremoto de 1906 en la vivienda popular de Valparaíso: Una síntesis", Revista CA, Ciudad y Arquitectura 126, Santiago de Chile, 2006, 30-31.

Urbina, María Ximena, Los conventillos de Valparaíso, 1880-1920. Fisonomía y percepción de una vivienda popular urbana, Valparaíso, Editorial Universitaria de la Pontificia Universidad Católica de Valparaíso, 2002a.

Valencia, Lucía, "Diversión popular y moral oligárquica: entre la barbarie y la civilización. Valparaíso, 1850-1880", Contribuciones científicas y tecnológicas 122, Santiago de Chile, 1999, 157-170.

Verani, Hugo, Las vanguardias literarias en Hispanoamérica (manifiestos, proclamas y otros escritos), México DF, FCE, 1995.

Walton, Julio, "Filigranas", Siembra 1, Valparaíso, 1920, s/n.

Walton, Julio, El hijo de nadie. Comedia de estudiantes y modistillas, Valparaíso, Ediciones Siembra, 1919.

Yurkievich, Saúl, "Rosa Náutica, un manifiesto del movimiento de vanguardia chileno", Bulletin de la Faculté des Lettres de Strasbourg 46:7, París, 1968, 649-655.

Zsigmond Remenyik, El lamparero alucinado, Madrid, Editorial Iberoamericana, 2009.

\section{Fuentes Digitales}

Grez Toso, Sergio. "Transición en las formas de lucha: motines peonales y huelgas obreras en Chile (1891-1907)", Historia 33, Santiago de Chile, 2000. Disponible en: http://revistahistoria.uc.cl/estudios/2012/

Silva Castro, Raúl, "Notas sobre la juventud literaria en Chile", Claridad 89, Santiago de Chile, 1923. Disponible en: http://www.claridad.uchile.cl/index.php/CLR/article/view/ 8035/7784.

Urbina, María Ximena, "Los conventillos de Valparaíso, 1880-1920: percepción de barrios y viviendas marginales", Revista de Urbanismo 5, Santiago de Chile, 2002b, 1-17. Disponible en: http://www.revistas.uchile.cl/index.php/RU/article/viewFile/12953/13237

\section{Documentación privada}

Carta de Neftalí Agrella a Monsieur Vincent Huidobro, Valparaíso 25 de abril de 1925. Archivo Fundación Vicente Huidobro, Museo de la Casa Colorada, Santiago de Chile. 